\section{Uncommon Association of Aortopulmonary Window in a Patient with Complex Univentricular Heart and CHARGE Syndrome}

Sathish Chikkabyrappa, M.D.,2, Guruprasad Mahadevaiah,

M.D. ${ }^{3}$, Arpan R. Doshi, M.D. ${ }^{4,5}$, Joan Lee, M.D. ${ }^{1,2}$,

Eyal Sagiv, M.D., Ph.D. ${ }^{1,2}$, Sujatha Buddhe, M.D.,2

'Seattle Children's Hospital, Division of Pediatric Cardiology, Seattle, WA

${ }^{2}$ University of Washington School of Medicine, Seattle, WA

${ }^{3}$ California Northstate University College of Medicine, Sacramento, CA

${ }^{4}$ Children's Cardiology Associates, Pediatrix Medical Services, Inc., Houston, TX

${ }^{5}$ University of Houston College of Medicine, Houston, TX Received Aug. 26, 2020; Accepted for publication Oct. 27, 2020; Published online Feb. 12, 2021 https: doi.org 10.17161/kim.voll414591

\section{INTRODUCTION}

The univentricular heart and aortopulmonary window (APW) are rare cardiac malformations and their association is extremely rare. Worldwide incidence of congenital heart disease (CHD) is estimated at 8 per 1,000 live births. ${ }^{1} \mathrm{APW}$ represents 0.1 to $0.6 \%$ of all CHD. ${ }^{2}$ The most associated malformations are aortic arch anomalies, specifically coarctation of the aorta and type A interruption of aortic arch, as well as atrial and ventricular septal defects and conotruncal anomalies.

Only a handful of case reports of APW associated with complex single ventricle lesions have been described in the literature. ${ }^{3,4}$ To our knowledge, there is no literature on association of CHARGE syndrome (Coloboma, Heart defect, Atresia choanae, Retarded growth and development, Genital hypoplasia, Ear anomalies/deafness) with complex univentricular heart and APW. We report a case of unique combination of large APW in a complex univentricular heart of undetermined morphology with malposed great arteries in a neonate with absent thymus and CHARGE syndrome. In addition, our patient's genetic testing was positive for CHD7 mutation.

\section{CASE REPORT}

A full-term, $2.5-\mathrm{kg}$, female neonate with prenatal diagnosis of complex single ventricle was transferred from an outside institution for stage one single ventricle palliation. She was born to a 23 -yearold, gravida 2, parity 2, Caucasian woman at 38 weeks of gestation. The pregnancy was complicated by pregnancy-induced hypertension and gestational diabetes. Her immediate postnatal course was uncomplicated without requiring any resuscitation. Initial oxygen saturations were in $90 \%$ range on room air without any signs of respiratory distress. Physical exam was significant for dysmorphism consistent with CHARGE syndrome (head-sparing short stature, hypertelorism, down-slanting palpebral fissure, iris coloboma, and microtia). Cardiac exam was significant for single first heart sound and nonspecific soft systolic murmur.

The transthoracic echocardiogram showed a complex univentricular heart with undetermined morphology. Both atria drained into the single ventricle via common atrioventricular (AV) valve. There was common atrium. There was malposition of great arteries with aorta
KANSAS JOURNAL of MEDICINE

anterior and rightward of the pulmonary artery with two normal semilunar valves. There was a large type III APW immediately distal to the semilunar valves, and both branch pulmonary arteries arose posteriorly from the large truncal artery. There was a left aortic arch with aberrant right subclavian artery with mildly hypoplastic distal aortic arch. There was no patent ductus arteriosus. The patient had bilateral superior vena cave and normal pulmonary venous drainage (Figures 1, 2, and 3).

Due to the complex great artery and arch anomalies, cross sectional imaging was obtained to confirm the above findings prior to surgical palliation (Figures 4 and 5). This anatomy was deemed to be non-ductal dependent cardiac lesion. Further work-up included a computed tomography (CT) scan of internal auditory canal, which revealed bilateral hypoplastic petrous ridge with dysplastic inner ears, absent semicircular canal, normal cochlear nerve, consistent with CHARGE syndrome. The cranial, abdomen and renal ultrasounds were unremarkable. Genetic testing confirmed the CHD7 mutation, supportive of CHARGE syndrome.

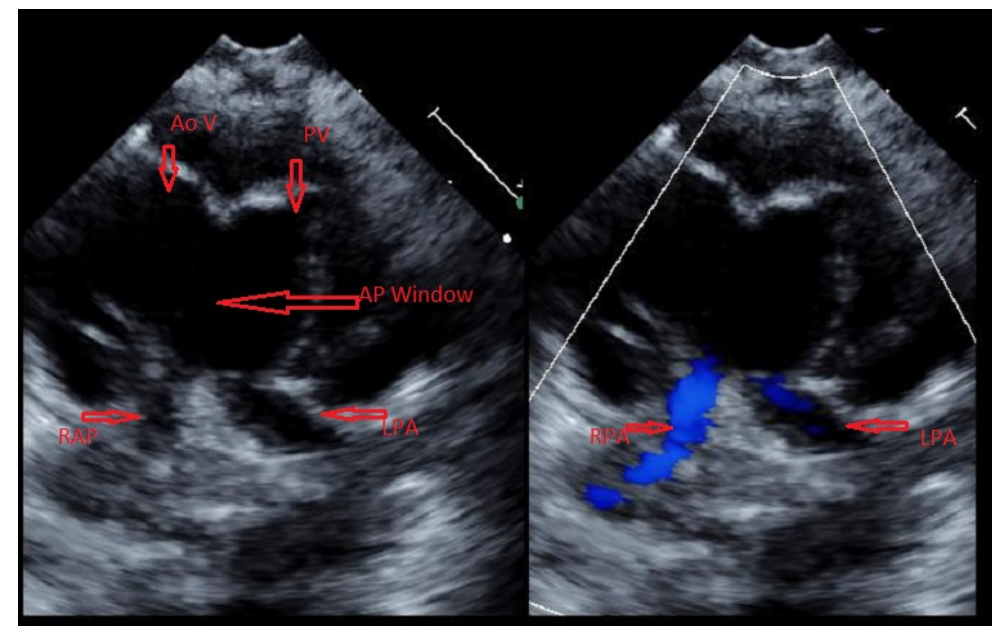

Figure 1. Parasternal short axis echocardiogram image on color comparison showing large aortopulmonary window with both branch pulmonary arteries coming off posterior portion of common trunk. (RPA-Right pulmonary artery, LPA-Left pulmonary artery, AoV-Aortic valve, PV-Pulmonary valve, AP Window-Aortopulmonary window).

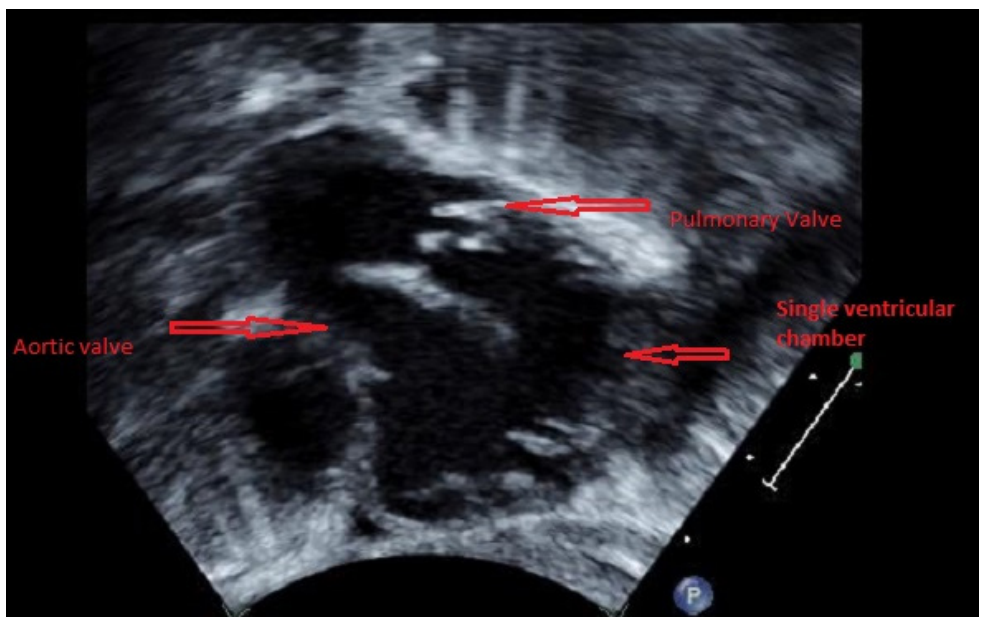

Figure 2. Subcostal 2D image depicting two semilunar valves arising side by side from a single ventricle of undetermined morphology. 


\section{KANSAS JOURNAL of MEDICINE AORTOPULMONARY WINDOW continued.}

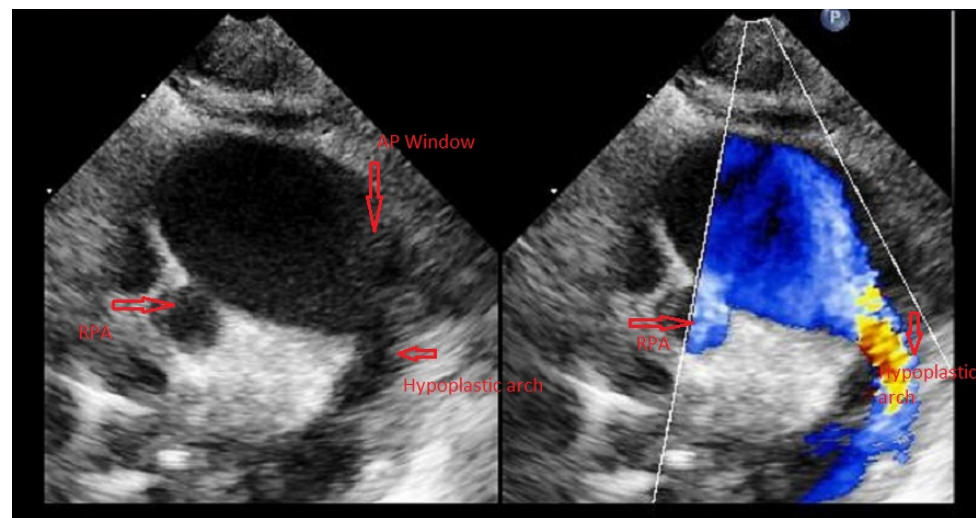

Figure 3. High parasternal transthoracic image with color comparison showing hypoplastic arch continues from the large AP window trunk and showing branch pulmonary artery from the posterior portion of trunk. (RPA-Right pulmonary artery, AP window-Aortopulmonary window).

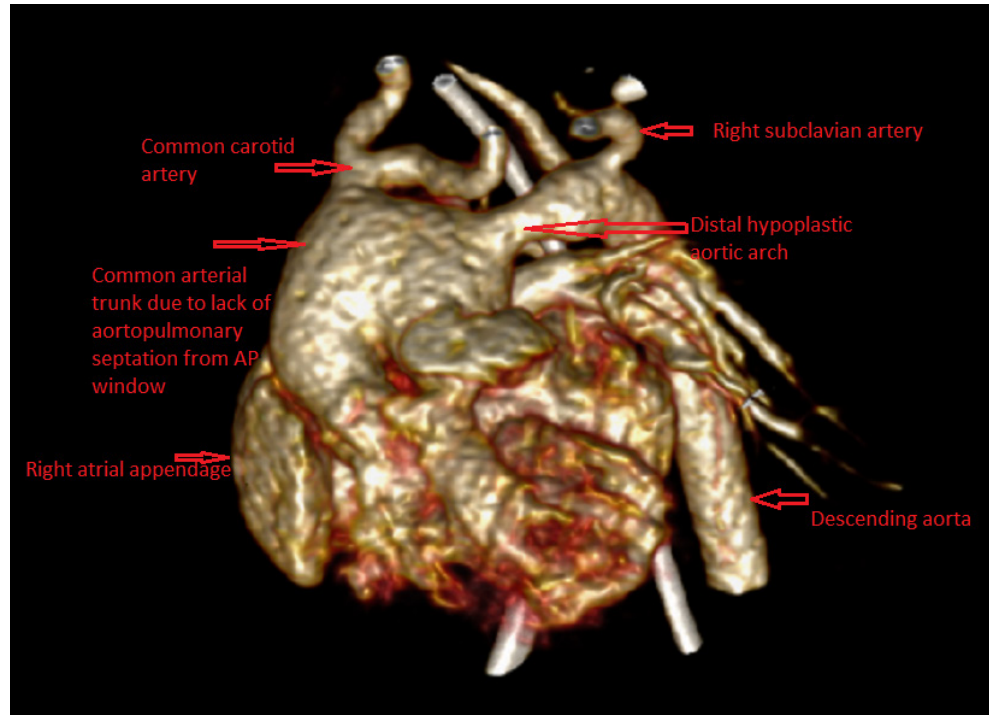

Figure 4. Reconstructed CT image anterior projection showing head and neck vessels and $\mathrm{AP}$ window in detail.

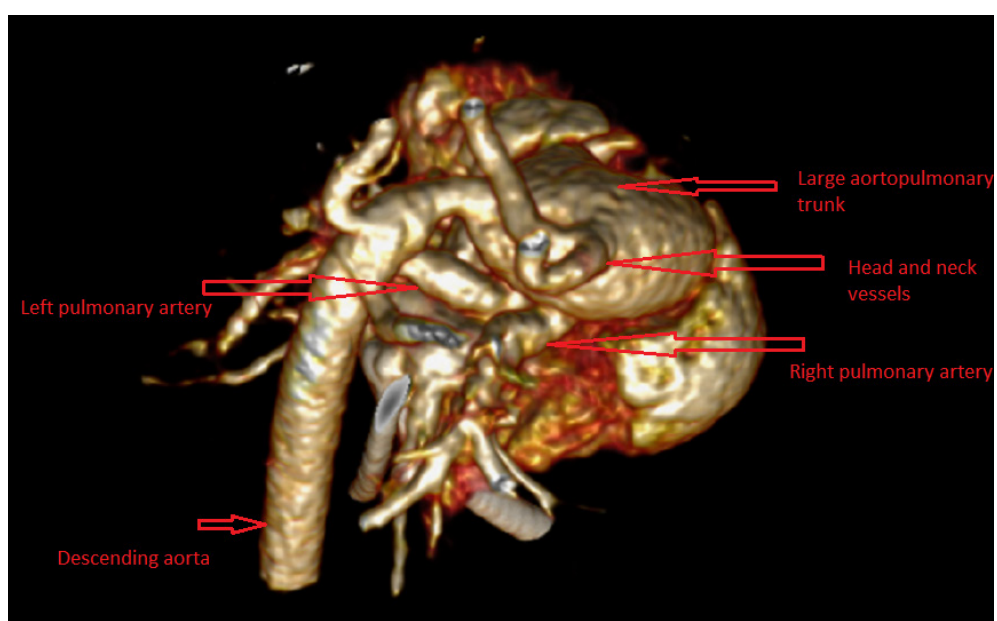

Figure 5. Reconstructed CT image posterior projection showing head and neck vessels and $\mathrm{AP}$ window in detail.
After extensive discussion in our combined cardiac surgery conference, she underwent aortic arch repair with APW repair, oversewing of pulmonary valve, and placement of $5 \mathrm{~mm}$ right ventricle to pulmonary artery conduit at six days of age. Interestingly, complete lack of thymic tissue was noted intraoperatively.

Post-operative course was complicated by hemodynamic instability, cardiac arrest, post-arrest seizure, and acute kidney injury. She underwent cardiac catheterization on day 13 post-surgery for persistent respiratory failure and hemodynamic lability, and had a stent implanted into her right pulmonary artery for stenosis. During the rest of the hospitalization, she underwent GI-tube placement for feeding, weaned off respiratory support and progressed to discharge from the hospital.

\section{DISCUSSION}

To our knowledge, this is the first case of a neonate with univentricular heart with common AV valve and an APW. There were two earlier case reports with APW in the setting of complex univentricular heart, one with tricuspid atresia and the other had double inlet ventricle with large ventricular septal defect.,

Univentricular hearts are uncommon and there is controversy about the definition, classification, and nomenclature. Van Praagh et al. ${ }^{5}$ has described them as hearts with one ventricular chamber that receives both atrioventricular valves or a common $\mathrm{AV}$ valve, excluding mitral and tricuspid atresia. Anderson et al. ${ }^{6}$ used the term "univentricular connection" in which both atria are committed to one ventricle (double inlet ventricle) or one of the $\mathrm{AV}$ valves is absent. The ventricle can be either right or left ventricle based on the morphologic characteristics or indeterminate. The most common type of univentricular AV connection is a double-inlet left ventricle with a hypoplastic right ventricle ${ }^{7}$ and comprise $1 \%$ of all the congenital heart defects. ${ }^{8}$

Our case was a rare combination of univentricular heart (indeterminate morphology) via a common AV valve and type III APW in an infant with CHARGE syndrome. This is a form of AV septal defect. Van Praagh et al., ${ }^{5,7}$ reported about 33\% had common AV valve in their series on "common ventricle". In the same series, situs ambiguous was frequent and polysplenia was present in about $40 \%$ of cases with common $\mathrm{AV}$ valve type. The double outlet right ventricle was seen often, or ventriculo-arterial (VA) connections were discordant with right or left anterior aorta or normally related. Pulmonary valve stenosis or atresia is frequently found. Embryologically, the AV valves develop from endocardial cushions and the interventricular septum develops with contributions from multiple regions including muscular growth from the developing common ventricle, membranous septum from endocardial cushions and bulbar septum from the aortopulmonary septum above. The failure of aortopulmonary septation leads to aortopulmonary window. In our case, there was failure of endocardial cushions and interventricular septum formation as well as aortopulmonary septation.

AP window is a condition in which there is persistent communication between the intrapericardial walls of aorta and pulmonary trunk. Mori et al. ${ }^{9}$ classified this condition into three types. Type I is a proximal defect between the ascending aorta and the pulmonary trunk and is located above the semilunar valves with only a slight inferior rim. Type II is absence of superior rim distally at the level of pulmonary artery 
bifurcation. Type III refers to a large defect that extends from above semilunar valves to the pulmonary artery bifurcation. Richardson's classification was similar to Mori's except the Type III referred to anomalous origin of one of the branch pulmonary artery from ascending aorta, with no other aortopulmonary connection. ${ }^{10}$ This Type III Richardson defect is no longer considered as a variant of AP window, but as a unique defect. The Society of Thoracic Surgeons Congenital Heart Surgery Database committee has accepted Mori's classification. They recognized a fourth variant, an "Intermediate" defect consisting of a smaller, central defect with a circumferential rim of tissue. ${ }^{2}$

Although there have been two previous reports of APW associated with single ventricle, our patient was unique in her association with CHARGE syndrome, which has not been reported. CHARGE syndrome initially was defined as a non-random association of anomalies (Coloboma, Heart defect, Atresia choanae, Retarded growth and development, Genital hypoplasia, Ear anomalies/deafness).,3 The cardiac anomalies are present in up to $75 \%$ of these patients. Septal defects and tetralogy of Fallot are most common cardiac defects in CHARGE syndrome.

APW usually is associated with arch anomalies and septal defects. In our patient's case, it was associated with a complex single ventricle physiology. Patients with CHARGE syndrome have additional morbidity and mortality risk related to increased obstructive sleep apnea, aspiration, and death, even without the presence of CHD. ${ }^{11-13}$ Patients with CHARGE syndrome are also at high risk for immunological dysfunction secondary to T-cell functional abnormalities and varying degrees of thymic hypoplasia. ${ }^{14}$ Our patient underwent first stage of single ventricle palliation, repair of APW and arch repair successfully.

\section{CONCLUSIONS}

Our case is a unique association of complex univentricular heart with common AV valve and type III APW, in the setting of CHARGE syndrome, confirmed by CHD7 mutation. It emphasized the importance of thorough evaluation in the presence of dysmorphic features.

\section{ACKNOWLEDGEMENT}

Dr. Sathish Chikkabyrappa and Dr. Guruprasad Mahadevaiah have equally contributed to the report.

\section{REFERENCES}

${ }^{1}$ Doshi AR, Chikkabyrappa S. Coarctation of aorta in children. Cureus 2018; 10(12):e3690. PMID: 30761242.

2 Jacobs JP, Quintessenza JA, Gaynor JW, et al. Congenital Heart Surgery Nomenclature and Database Project: Aortopulmonary window. Ann Thorac Surg 2000; 69(4 Suppl):S44-49. PMID: 10798415.

${ }^{3}$ Salve GG, Jain SA, Katkade SS, Shivaprakash K. Complex aortopulmonary window in a single ventricle setting: Technical considerations for staged palliation. Ann Pediatr Cardiol 2016; 9(2):167-169. PMID: 27212854.

${ }^{4}$ Milovanovic V, Stefanovic I, Ilic S. Tricuspid atresia associated with aortopulmonary window: Diagnostic and therapeutic dilemmas. Cardiol Young 2017; 27(3):580-583. PMID: 27680574.

${ }^{5}$ Van Praagh R, Ongley PA, Swan HJ. Anatomic types of single or common ventricle in man: Morphologic and geometric aspects of 60 necropsied cases. Am J Cardiol 1964; 13:367-386. PMID: 14128647.

6 Anderson RH, Becker AE, Wilkinson JL. Proceedings: Morphogenesis and nomenclature of univentricular hearts. Br Heart J 1975; 37(7):781-782. PMID: 1156496.

7 Van Praagh R, Van Praagh S, Vlad P, Keith JD. Diagnosis of the anatomic types of single or common ventricle. Am J Cardiol 1965; 15:345-366. PMID: 14263032.

${ }^{8}$ Franklin RC, Spiegelhalter DJ, Anderson RH, et al. Double-inlet ventricle presenting in infancy. I. Survival without definitive repair. J Thorac Cardiovasc Surg 1991; 101(5):767-776. PMID: 2023434.
KANSAS JOURNAL of MEDIC INE

AORTOPULMONARY WINDOW

continued.

9 Mori K, Ando M, Takao A, Ishikawa S, Imai Y. Distal type of aortopulmonary window. Report of 4 cases. Br Heart J 1978; 40(6):681-689. PMID: 656242.

10 Richardson JV, Doty DB, Rossi NP, Ehrenhaft JL. The spectrum of anomalies of aortopulmonary septation. J Thorac Cardiovasc Surg 1979; 78(1):21-27. PMID: 449383.

11 White DR, Giambra BK, Hopkin RJ, Daines CL, Rutter MJ. Aspiration in children with CHARGE syndrome. Int J Pediatr Otorhinolaryngol 2005; 69(9):1205-1209. PMID: 15890414.

12 Bergman JEH, Blake KD, Bakker MK, du Marchie Sarvaas GJ, Free RH, van Ravenswaaij-Arts CMA. Death in CHARGE syndrome after the neonatal period. Clin Genet 2010; 77(3):232-240. PMID: 20447140.

13 Trider CL, Corsten G, Morrison D, Hefner M, Davenport S, Blake, K. Understanding obstructive sleep apnea in children with CHARGE syndrome. Int J Pediatr Otorhinolaryngol 2012; 76(7):947-953. PMID: 22542139.

${ }^{14}$ Wong MTY, Lambeck AJA, van der Burg M, et al., Immune dysfunction in children with CHARGE syndrome: A cross-sectional study. PLoS One 2015; 10(11):e0142350. PMID: 26544072.

Keywords: CHARGE syndrome, aortopulmonary septal defect, univentricular heart, neonate, case report 